\title{
Assessing the Impact of Employee Work Design on Performance and Profit Optimization of Nigerian Commercial Banks
}

\author{
Marcus Garvey Orji ${ }^{1}$, Regina Samson ${ }^{2}$, Solomon Abba Boman ${ }^{2}$, Joseph Odey ${ }^{3}$ \\ ${ }^{1}$ Department of Business Administration, Veritas University, Abuja, Nigeria \\ ${ }^{2}$ Department of Business Administration, Faculty of Administration, Ahmadu Bello University, Zaria, Nigeria \\ ${ }^{3}$ Department of Marketing, University of Nigeria, Nsuka, Nigeria
}

Email address:

orjimarcusgarvey@yahoo.com (M. G. Orji)

\section{To cite this article:}

Marcus Garvey Orji, Regina Samson, Solomon Abba Boman, Joseph Odey. Assessing the Impact of Employee Work Design on Performance and Profit Optimization of Nigerian Commercial Banks. International Journal of Economic Behavior and Organization.

Vol. 5, No. 1, 2017, pp. 8-14. doi: 10.11648/j.ijebo.20170501.12

Received: October 31, 2016; Accepted: January 7, 2017; Published: February 22, 2017

\begin{abstract}
The major problem confronting most human resources managers in organization is how can a job be designed or structured so that the employee's performance can be enhanced and profitability increased. There is the need to understand that how workers responsibilities and duties are segmented helps to shape and determine virtually all other facets of organizational functioning. This research work has the objective of assessing the impact of work design on profit optimization of Nigerian commercial banks. The study adopted a survey research method and both primary and secondary sources of data were applied. Formulated hypotheses were tested using regression analysis. The findings of the study revealed that Work design enhances productivity in banks, Work design increases profitability, influences behavior, staff motivation and autonomy in banks. The study recommends that Work should be design to influence potential behavior in line with technological trends, and Management should endeavour to discourage the notion that work design exercises are carried out for performance evaluation purposes only. This can be done by laying more emphasis on training and retraining of staff to fit into ever changing information technology especially in banks.
\end{abstract}

Keywords: Work Design, Employee Performance, Profit Optimization, Commercial Banks

\section{Introduction}

Organisations have evolved because the overall mission and objectives of most institutions are too large for any single person to accomplish. Consequently, the organisation must have a systematic way to determine which employees are expected to perform a particular job or task, how to structure job elements and duties to achieve optimal productivity.

An organisation's staff is one of the most critical factors with respect to its output and profitability. The competitiveness of an organisation results from the total sum of its' work-related activities. Similarly, the quality of an organisations performance is determined by how employees accept their tasks and dedicate their efforts wholeheartedly with passion and creativity [1]. Thus optimal performance of an organisation would be achieved when optimal employees were placed according to job requirements and employees were changed as jobs were designed effectively.

As the size of corporate organization becomes larger, the interest in jobs and job characteristics also increase. Kim \& Lee [1] suggests that attributes of a specific job induces psychological conditions of organisation's members, and that by using this employees can be motivated to improve organisational performance

Traditionally, organisations have approached job performance and system efficiency through staff development and training. Training continues to be an important part of the appropriate utilization of human resources but underutilization can be influenced by many variables. Organisational literature identifies that underutilization can be related to the design of the work [2]. Restructuring the design of work offers opportunities to enact 
full scopes of practice, minimize performance uncertainty and performance pressure, boost work satisfaction and work motivation, foster high quality work performance and promote effective work delivery.

The cornerstone of the organisation is therefore the set of jobs performed by its employees. These jobs in turn, provide the mechanism for coordinating and linking the various activities of the organisation that are necessary for success and profit optimization [3].

As a result, studying and understanding job, structuring job elements, duties and tasks in a manner that will help achieve optimal performance, satisfaction and profitability through the process of job design is a vital part of any Human Resources Management in an organisation. It is in the light of this that this study intends to assess the impact of job design on the performance and profit optimization of Nigerian commercial banks.

\subsection{Statement of the Problem}

There is the need to understand that how workers responsibilities and duties are segmented helps to shape and determine virtually all other facets of organisational functioning. As such understanding exactly what constitutes any particular job is critical to developing human resources activities that support the organisation's mission and objectives of profit optimization.

However, the effectiveness of job design in optimizing profits in the Nigerian banking industry is yet to be attended. Also, ascertaining whether or not any significant relationship exists, between investment in job design and profit is still a nightmare to them. Besides, the challenges inherent in designing the job that will yield optimal result (profitability) are yet to be tackled by Nigeria commercial banks.

\subsection{Research Questions}

On the whole this study is to provide answers to some pertinent questions like;

(1) Is there any significant relationship between investment in employee job design and profit optimization of Nigerian commercial banks?

(2) Does any significant relationship exist between employee job satisfaction and profit optimization of Nigerian commercial banks?

(3) Are there any significant relationship between employee job motivation and profit optimization of Nigerian commercial banks?

(4) Does employee work design enhance performance and productivity in Nigerian commercial banks?

\subsection{Objectives of the Study}

The main objective of this study is to assess the impact of employee work design on profit optimization of Nigerian commercial banks.

To achieve this, the following secondary objectives would be also considered;

(1) To determine whether there is significant relationship between investment in employee job design and profit optimization of Nigerian commercial banks.

(2) To assess if any significant relationship exist between employee job satisfaction and profit optimization of Nigerian commercial banks.

(3) Ascertain whether there is any significant relationship between employee job motivation and profit optimization of Nigerian commercial bank.

(4) Assess whether employee work design enhance performance and productivity in Nigerian commercial banks.

\subsection{Hypotheses of the Study}

The following null hypothetical assumptions have been postulated for validation in this study;

$\mathrm{H}^{01}$; There is no significant relationship between investment in employee job design and profit optimization of Nigerian commercial banks.

$\mathrm{H}^{02}$; There is no significant relationship between employee job satisfaction and profit optimization of Nigerian commercial banks.

$\mathrm{H}^{03}$; There is no significant relationship between employee job motivation and profit optimization of Nigerian commercial bank.

$\mathrm{H}^{04}$; There is no significant relationship between employee job design, performance and productivity in Nigerian commercial banks.

\subsection{Scope of the Study}

The scope of this research work is limited to the issues of employee job design, work satisfaction arising from work design, work motivation, performance and profit optimization in Nigerian commercial banks. In this regards, two commercial banks are focus as case study, First Bank Nigeria plc and Unity banks plc, between 2010-2015 (5 years financial period). Emphasis will be on Abuja and its environs branches of the banks.

\section{Literature Review}

\subsection{Conceptual and Theoretical Framework}

\section{Work design}

According to Armstrong [4], work design specifies the contents, methods and relationships of jobs in order to satisfy work requirements for productivity, efficiency and quality, meet the personal needs of the job holder and thus increase levels of employees engagement.

Ivancevich [3] in his own view described work design as structuring of work elements, duties and tasks in a manner that will help to achieve optimal performance and satisfaction.

Nwachukwu [5], defined work design as the specification of the content, methods and relationships of a job in order to satisfy technological and organizational requirements as well as the social and personal requirements of the job holder.

Job design has also been defined as "the process to 
optimize organizational goals of efficiency and productivity and how workers can be satisfied doing it, optimizing individual goals of personal growth and wellbeing. The meaning derived from these definitions refers to work design as something that is used and decided upon by managers of the organization [3]

For our purpose, work design is the critical assessment of job to determine the work content, method content, organizational content and personal content, thereby assigning such job to a suitable and qualified employee to enhance performance and productivity. Thus, any work design that must be effective must enhance performance and productivity in an organization.

The process of work design starts with an analysis of the way in which work needs to be organized and what work therefore needs to be done; the task has to be carried out if the purpose of the organization or an organizational unit is to be achieved [4].

\section{Profitability}

In neoclassical microeconomic theory, the term profit has two related but distinct meanings. Economic profit is similar to accounting profit but smaller because it reflects the total opportunity costs (both explicit and implicit) of a venture to an investor Albrecht [6]. Normal profit refers to a situation in which the economic profit is zero. A related concept, sometimes considered synonymous to profit in certain contexts, is that of economic rent.

In Classical economics and Marxian economics, profit is the return to an owner of capital goods or natural resources in any productive pursuit involving labor, or a return on bonds and money invested in capital markets Carbaugh, [7]. By extension, in Marxian economic theory, the maximization of profit corresponds to the accumulation of capital, which is the driving force behind economic activity within the capitalist mode of production.

Other types of profit have been referenced according to Carbaugh,[7], including social profit (related to externalities). It is not to be confused with profit in finance and accounting, which is equal to revenue minus only explicit costs, and super profit, a concept in Marxian economic theory.

Profit may be expressed as the proportion by which the price per unit sold exceeds its cost that is, as a rate on turnover.

Although profit is a reward to one of the factors of production, it differs in several respects from the income payable to the other factors. Profit is a residual reward payable to the entrepreneurs after all the other costs of the business have been met, where as labour can be certain of its weekly wage or monthly salary, and the debenture holder fairly certain of his interest, there is no guarantee that the ordinary shareholder will receive a dividend.

\subsection{Approaches to Work Design}

Ivancevich [3] identified four major categories or approaches in which work design can be classified as;

(1) The perceptual- motor approach

(2) The biological approach
(3) The mechanistic approach, and

(4) The motivational approach

1. Scientific and mechanical approach; Job design was a central issue in F, W Taylor's model of scientific management. His use of job design is an excellent example of the rational approach and shows how certain perspectives focus more on productivity than on satisfaction. The work of Taylor and the principles of scientific management initiated a great deal of interest in systematic studying the structure of jobs. The emphasis was clearly on structuring jobs so that they were broken down into simple, repetitive tasks. Once learned these tasks could be done quickly and effectively.

2. Job Enrichment; a Mechanical approach; In the past two decades, much attention has been directed at changing jobs in more meaningful ways than job enlargement was able to do. Rather than simply increasing the variety of tasks performed by an employee. The notion of satisfying employees needs as a way of designing jobs comes from Frederic Herzberg's two-factor theory of work motivation. His basic idea is that employees will be motivated by jobs that enhance their feelings of self worth. Although there are many different approaches to job enrichment, the job characteristics model is one of the mostly publicized. This model shows that for a job to lead to desired outcomes it must possess core job dimensions which include- skill variety, task identity, task significance, autonomy and feedback [3].

Work Characteristics

Work or Job characteristics as propounded by various scholars are discussed below:

Skill Variety: Hackman and Oldham [8] defined skill variety as the opportunity to use a number of valued skills and abilities. Robert \& Paul [2] had argued that enriched or complex jobs promote increased satisfaction and motivation while others report that organizational climate moderates the relationship between job satisfaction and job complexity.

Role identity: Role identity has its roots in the job characteristic named task identity as identified by Hackman and Oldham [8].

Work Feedback: Feedback from the job reflects the degree to which the job provides clear and direct information about one's effectiveness of performance [8].

Accountability: Lawler, \& Martiuko, [9] describe accountability as the "willingness to be answerable for one's actions". Hackman \& Oldham [8] identified that responsibility as a psychological state must be activated for optimal job satisfaction, motivation and work performance to be achieved. Lawler,\& Martiuko, [9] suggest that to be responsible and accountable, employees must have not only the competency to provide service but also the authority to provide service on the basis of their professional knowledge and judgement. Wolf [10] suggest that the way employees experience empowerment has a direct effect on work effectiveness as well as an indirect effect through employee perception of accountability. This 
highlights the importance of work environments.

Empowerment: Empowerment is suggested here as a work characteristic rather than as an outcome of a well-designed job because of the factors that influence empowerment. Wolf [10] summarize empowerment theory into two themes, namely psychological and structural. The first theme, psychological empowerment, relates to perception of empowerment and increased intrinsic task motivation which is influenced by the psychological variables of choice, competence, meaningfulness and impact. Choice (or selfdetermination) refers to using one's judgment and taking responsibility for one's actions. Choice could also be related to ones feelings of control over work. Competence is the degree to which one can perform skillfully. Meaningfulness refers to value-added of one's work. Impact refers to the degree to which one's actions are seen as making a difference. These variables are similar to the three psychological states defined in the Job Characteristics Model - i.e. experienced meaningfulness, knowledge of results, and experienced responsibility. The second theme, structural empowerment, relates to the structural variables that impact on empowerment. As discussed under accountability, these include having access to resources as well as information, receiving support and having opportunities to learn and grow. Although these structural variables enhance empowerment, empowerment is not something that one can give to someone else. It is a recognition and application of the power that is already present in a job. To further enhance empowerment, roles and expectations must be clear.

Knowledge: Knowledge is a work characteristic that was not uniquely identified in the literature but is identified here as a characteristic to address concepts such as decision-making, problem solving, information processing, innovation idea generation and even specialization. Of interest is Wolf [10] concept of cognitive task boundaries which refers to understanding how one sees their job, that is, as a set of discrete pieces or as an integrated whole. Thus, knowledge work requires continuous learning and teaching by the knowledge worker. Knowledge and decision-making are influenced by accountability and control. Greater autonomy will enhance the acquisition and utilization of knowledge [11]. In highly autonomous settings, employees learn to anticipate and prevent errors as well as dealing with variances.

Interdependence: In work design literature, interdependence refers to the degree in which a job depends on others or others depend on it to complete the work. Hacker, [11] further defines interdependence by suggesting that interdependence has three dimensions, namely scope, resources and criticality. The potential for increased knowledge and knowledge sharing through collaboration and interaction with others raises the importance of opportunities for interdependence. On the other hand, Ganguli [12] expect that more interdependence impacts negatively on the opportunity to personally shape or mould ones job.

\subsection{Impact of Work Design in Banks}

Work design can be viewed as a system of highly interactive processes which involve personnel at all levels in differing degrees in determining job expectations, writing job descriptions, developing assessment tools and procedures, and collecting interpreting, and reporting results.

Objectives for work design in banks can best be understood in terms of potential benefits. Armstrong [4] identify the following:

(1) Influence skill variety by providing opportunities for staff to do several tasks and by combining tasks, such as paying cashier and receiving cashier

(2) Influence autonomy by giving people responsibilities for determining their own working system, such as receiving cashier using queing model to attend to customers

(3) Increase motivation to perform effectively

(4) Increase staff self-esteem

(5) Gain new insight into staff and supervisors

(6) Better clarify and define job functions and responsibilities

(7) Encourage increased self-understanding among staff as well as insight into the kind of development activities that are of value

The overriding purpose of work design is to help staff to be diligent and improve productivity. It is only when productivity is increased that profitability can be guranteed.

\subsection{Measuring Profitability in an Organisation}

A bank employee wage, for example, is predetermined and certain in amount, but the income of his employer is not. The man is paid now for goods or services produced, in anticipation of further demands, and since the future can never be foreseen, with certainty, the goods and services which the employer obtains for a given wage payment are of uncertain value. If eventually the price which the goods and services realize exceeds the cost incurred in their production, the employer will make a profit. This is how the concept of profitability applied, or profitability is measured in an organisation. If on the other hand the selling - price turns out to be lower than the cost which the organization has incurred, it will make a loss. But the organisation does not, and cannot know in advance with $100 \%$ surety that it will be able to make a profit. It certainly expects to make a profit, but may be unlucky [13]. Thus, profitability is measured based on the differences between the return on investment and the cost of investment.

\section{Methodology}

This study has been designed in line with survey research using data collected from both primary and secondary sources. The secondary sources comprise of mainly text books, journals and periodicals, while primary source was descriptive survey questionnaires and for the relationship between variables was the regression analysis. In this study, the target is to determine the extent of relationship between employee job design, job satisfaction, job motivation, work performance (predictor variables) and profit optimization of 
banks in Nigeria.

Since every member of the population can not be reached, this study selected 200 respondents using purposive random sampling, whereby the researcher uses his/her value judgment to select respondents from the population whose opinions the researcher feels relevant to make a valuable decision. The adapted questionnaires were administered randomly in different branches of First bank plc and Unity bank plc within Abuja and its environ 148 were returned valid representing $74 \%$, which is valid enough to form opinion. 4-level Likert answer range was applied. Cronbach alpha was used to estimate the stability of the questionnaires with 0.88 and 0.83 , respectively, and Regression analysis was used. SPSS software version 20 was applied.

The model formula used is given as;

$$
\mathrm{Y}=\mathrm{a}+\mathrm{b} 1 \times 1+\mathrm{b} 2 \times 2 \text {. }
$$

Thus; $\mathrm{Y}=\mathrm{X}+\beta 1 X 1+\beta 2 X 2+\beta 3 X 3+\beta 4 X 4---+\beta n X n$.
Where, $\mathrm{a}=$ constant

$$
\beta=\text { Coefficient of the varriables }
$$

$\mathrm{X}=$ Independent Variables $(\mathrm{X} 1=$ Training, $\mathrm{X} 2=\mathrm{Job}$ satisfaction, $\mathrm{X} 3=$ Job motivation, $\mathrm{X} 4=$ Work performance). The Dependent variable is Profit optimization as a result of increases in patronage and turnover.

\section{Results/Findings}

To assess the effectiveness of each aspect of the predictor variable (investment in job design by training, work satisfaction, motivation and work performance) multiple regression models was used. " $F$ " in table 2 considering sig $=0$ at 0.95 means that regression is meaningful. at $95 \%$ confidence level.

Table 1. Variance analysis of the impact of job design on profit optimization of Nigerian

\begin{tabular}{lllllll}
\hline ANOVA $^{\mathbf{a}}$ & & & & & & \\
\hline Model & & Sum of Squares & Df & Mean Square & F & Sig. \\
\hline \multirow{3}{*}{1} & Regression & 9.138 & 4 & 2.284 & 8.288 & $.000^{\text {b }}$ \\
& Residual & 38.591 & 140 & 10.276 & & \\
& Total & 47.729 & 144 & & & \\
\hline
\end{tabular}

a. Dependent Variable: Profit optimization

b. Predictors: (Constant), training, job satisfaction, job motivation, work performance

\begin{tabular}{|c|c|c|c|c|c|c|}
\hline \multicolumn{7}{|c|}{ Coefficients $^{\mathrm{a}}$} \\
\hline \multirow{2}{*}{ Model } & & \multicolumn{2}{|c|}{ Unstandardized Coefficients } & \multirow{2}{*}{$\begin{array}{l}\text { Standardized Coefficients } \\
\text { Beta }\end{array}$} & \multirow{2}{*}{$\mathbf{t}$} & \multirow{2}{*}{ Sig. } \\
\hline & & B & Std. Error & & & \\
\hline \multirow{5}{*}{1} & (Constant) & 2.307 & 0.246 & & 9.396 & .000 \\
\hline & Training & 0.158 & 0.117 & 0.19 & 1.348 & .000 \\
\hline & Satisfaction & 0.131 & 0.119 & 0.162 & 1.094 & .000 \\
\hline & Motivation & 0.039 & 0.087 & 0.052 & 0.447 & .032 \\
\hline & Performance & 0.053 & 0.085 & 0.076 & 0.617 & .000 \\
\hline
\end{tabular}

Table 2. Regression factors of the predictor variables on profit optimization.

a. Dependent Variable: Profit optimization

On the basis of "B", regression equation can be as follows:

$\mathrm{Y}=2.37+(0.158) \mathrm{X} 1+(0.131) \mathrm{X} 2+(0.039) \mathrm{X} 3+(0.053) \mathrm{X} 4$

Analysis shows a positive relationship as all the ' $t$ ' statistics of predictor variables are positive. Regarding "B", training factor $\left(\mathrm{X}_{1}\right)$ is bigger than the other values. Also, its Beta value is higher which shows that this factor has a bigger share profit optimization as ' $t$ ' statistics is higher than all. Therefore, the result of the regression analysis above revealed that there is a significant relationship between employee job design and profit optimization of Nigerian commercial banks.

\section{Conclusion}

It can be said that the variables used in designing works are mostly the ultimate yardstick for measuring an organization's performance and profitability/profit optimization. This research study draws its conclusion on the fact that work design practice in banks offers a valuable opportunity to focus on work activities and goals to identify and correct existing employees' problems and to encourage better future performance and improved productivity and profit optimization.

\section{Recommendations}

Based on the findings of this research study, we hereby make the following recommendations;

(1) As much as employees' development is important in the organisation's policies, subordinates should be allowed to express their capabilities by designing works according to their available skills.

(2) Work should be design to influence potential behavior 
in line with technological trends.

(3) Management should endeavour to discourage the notion that work design exercises are carried out for performance evaluation purposes only. This can be done by laying more emphasis on training and retraining of staff to fit into ever changing information technology in banks.

\section{Appendix}

Questionnaire

Please tick ' $x$ ' as appropriate

1. Gender:
Male
[ ] Female
[]

2. Marital status

Single [] Married

3. Qualification
(a) Masters Degree and above []
(b) B.Sc /HND
(c) Diploma
(d) School cert. and below

4. For how long have you worked with Your Bank?
(a) $1-5$ years
[]
(b) $6-10$ years
(c) $11-15$ years
(d) Above 15 years
[]

5. Official status
(a) Top Management
[]
(b) Middle Management
(c) Supervisory Management []
(d) Junior staff [ ]

6. Work design enhances productivity in your bank?
(a) Strongly agreed
(b) Agreed
[]
(c) Disagreed
(d) Strongly disagreed [ ]

7. Work design influences behavior in your banks?
(a) Strongly agreed
[]
(b) Agreed
(c) Disagreed
(d) Strongly disagreed [ ]

8. Work design influences staff motivation in your bank?
(a) Strongly agreed
[]
(b) Agreed
[]
(c) Disagreed
[]
(d) Strongly disagreed
[ ]

9. Work design influences staff autonomy and skill development in your bank?
(a) Strongly agreed
[]
(b) Agreed
(c) Disagreed
[]
(d) Strongly disagreed
[]

10. Work design influences your customer satisfaction?
(a) Strongly agreed
[]
(b) Agreed
(c) Disagreed
(d) Strongly disagreed

11. Your customer's satisfaction influences their further patronage?
(a) Strongly agreed
(b) Agreed
(c) Disagreed
(d) Strongly disagreed
[]

12. Your customer's further patronage increases your bank's turnover?
(a) Strongly agreed
(b) Agreed
(c) Disagreed
(d) Strongly disagreed

13. Increases in your bank's turnover results to increase in profit?
(a) Strongly agreed
(b) Agreed
(c) Disagreed
(d) Strongly disagreed

14. Suggest how best work design efforts of your bank can be managed to achieve Profitability and increase in market share.

\section{References}

[1] Kim. G \& Lim. Y. M (2016) Towards High Performance Organization: The Impacts of Job Characteristics and Job Crafting International Journal of $u$ - and e-Service, Science and Technology Vol.9, No. 2 (2016), pp.85-100.

[2] Robert, U. S \& Paul. G. D (2015) The Impact of Effective Work Design in Achieving Profitability in Organization (A Case Study of Selected Companies in Nigeria) International Journal of Humanities Social Sciences and Education (IJHSSE) VoL 2, (1), PP 144-152. 
[3] Ivacevich, J. M, (2009) "Human Resource Management" McGrawhill International Edition, New york.

[4] Armstrong, M. (2010) 'Human Resources Management Practice; A guide to People Management" Kogan Page, New Delhi.

[5] Nwachukwu, C. C (1988) "Management Theory and Practice" Africana -fep publishers Onitsha.

[6] Albrecht, W. P. (1983). Economics. Englewood Cliffs, New Jersey: Prentice-Hall.

[7] Carbaugh, Robert J. (January 2006). Contemporary economics: an applications approach. Cengage Learning.

[8] Hackman, J. R. \& Oldham, G. R. (1976). Motivation through the design of work: Test of a theory. Journal of Organizational Behavior and Human Performance, 16, 250279.
[9] Lawler, F. \& Martiuko, M. J. (1979). "The Practice of Supervision and Management. McGraw-Hill International Book Co. London.

[10] Wolf, E. T. (2005). "Organisation and Management". Macdonald and Evans Ltd. Estover.

[11] Hacker, W. (2003). Action regulation theory: A practical tool for the design of modem work. European Journal of Work and Organizational Psychology, 12, 105-130.

[12] Ganguli, C. H. (2001). "Industrial Productivity and Motivation". Asia Publishing House, London.

[13] Ejiogu, O (2012) Assessment of the influence of new product development on profitability in Nigerian Banks. Unpublished $M B A$ project. Department of business administration, A. B. U, Zaria. 